\title{
Comparação entre os testes de eritroimunoadsorção por captura, imunoenzimático e hemaglutinação passiva utilizados no diagnóstico da neurocisticercose
}

\author{
Comparison of the erythroimmunoadsorption by capture, immunoenzymatic \\ and passive haemagglutination tests used in the diagnosis of \\ neurocysticercosis
}

\author{
C. S. M. Pialarissi, S.M. O. O. Nitrini \\ Instituto Adolfo Lutz - Săo Paulo - Brasil (C.S.M.P.) \\ Departamento de Prática de Saúde Pública da Faculdade de Saúde PúblicalUSP - São Paulo - Brasil \\ (S.M.O.O.N.)
}

\begin{abstract}
Foi realizada a comparaçâo entre os testes de eritroimunoadsorção por captura (EIAC), imunoenzimático (ELISA) e de hemaglutinação passiva (HAP) utilizados no diagnóstico da neurocisticercose. Foram comparados dois testes já anteriormente utilizados na rotina diagnóstica da neurocisticercose (ELISA e HAP) e um recentemente padronizado (EIAC) para a deteção de anticorpos anti-Cysticercus cellulosae. $O$ antigeno empregado nos três testes foi $O$ extrato salino bruto (ESB), com um rendimento de 0,$1 ; 1$ e $1 \mu \mathrm{g}$ proteina/cavidade para os testes EIAC, ELISA e HAP, respectivamente. Quando se analisou um grupo de 58 pacientes com neurocisticercose, a sensibilidade observada fo de $98,2 \%, 84,5 \%$ e $77,2 \%$ nos testes ELISA, EIAC e HAP, respectivamente, para um grupo controle de 85 indivíduos, saudáveis ou com outras encefalotipatias, mas sem neurocisticercose, a especificidade foi de $94,1 \%, 95,3 \%, 91,8 \%$, respectivamente, nos testes. Esta ordem de escolha poderia ser obedecida na medida dos recursos dispon/veis.
\end{abstract}

Cisticercose, diagnóstico. Técnicas de imunoadsorçäo, utilização. ELISA, utilizaçäo. Testes de hemaglutinação. utilização.

\section{Introdução}

A neurocisticercose é uma doença causada pela larva de Taenia solium, podendo acarretar alteraçōes do sistema nervoso central.

Alguns métodos diagnósticos modernos estão sendo utilizados, tais como a tomografia computadorizada e a ressonância magnética, mas por seu alto custo são ainda inviáveis na maioria dos serviços de saúde pública.

As reações sorológicas ainda continuam sendo de grande auxílio no diagnóstico da neurocisticercose e diferentes testes imunodiagnósticos vềm sendo utilizados na pesquisa de anticorpos específicos da neurocisticercose tais como: imunoeletroforese $e^{6.7}$, imunofluorescência indireta ${ }^{12}$, hemaglutinação passiva $a^{3.12 .15 .16}$, e testes imunoenzimáticos ${ }^{1.4 .5}$. Na neurocisticercose, o exame do líquido cefalorraquidiano é realizado rotineiramente para o diagnóstico, e suas altereações caracterizam a síndrome liquórica da neurocisticercose, conceituada por Lange $^{9}$ em 1940.

Ueda e col. ${ }^{15,16}$ padronizaram a reação de hemaglutinação passiva (HAP) em 204 amostras de líquido cefalorraquidiano (LCR), tendo como antígeno o extrato salino total, obtendo a sensibilidade de $81,7 \%$ e especificidade de $94,4 \%$, quando empregavam hemácias humanas, e senbilidade de $88,7 \%$ e especificidade de 96,6 , quando utilizavam hemácias de carneiro, sem diferença estatisticamente significante entre a eficiência de ambos. 
O teste imunoenzimático (ELISA) foi utilizado para a cisticercose em 1978, por Arambulo e col. ${ }^{1}$ No Brasil o teste ELISA foi inicialmente realizado com antígeno de $C$. cellulosae utilizando o extrato salino total, extrato alcalino do líquido vesicular, extrato de escólex e o extrato de membrana, aplicados em 182 amostras de soro e em 115 amostras de LCR. A sensibilidade no soro variou entre 62,8 e $88,6 \%$, e a especificidade foi sempre de $100 \%$ (Costa e col. ${ }^{4}$, Costa ${ }^{5}$ ).

$\mathrm{O}$ teste ELISA foi empregado por Pialarissi e col. ${ }^{12}$, tendo como antígeno o extrato salino total, com sensibilidade de $97,6 \%$, em 125 LCR de pacientes com neurocisticercose, e especificidade de $98,9 \%$, em 94 LCR controles.

$O$ teste de eritroimunoadsorção por captura (EIAC) foi usado inicialmente por Krechee Whilhem ${ }^{8}$ em 1979, quando detectaram anticorpos da classe IgM na rubéola, por modificação do teste de inibição de hemaglutinação.

Pialarissi e Nitrinil3 utilizaram o teste eritroimunoadsorção por captura (EIAC) na detecção de anticorpos da classe IgG que é a principal imunoglubulina do LCR na neurocisticer$\operatorname{cose}^{14}$, na resposta imune humoral do hospedeiro.

O objetivo do presente trabalho é a comparação entre o desempenho dos testes HAP, ELISA e EIAC quando aplicados ao diagnóstico clínico da neurocisticercose na detecção de anticorpos antiCysticercus cellulosae. Verificou-se o comportamento de EIAC, uma reação recentemente padronizada, e com boas possibilidades de utilização em laboratórios de saúde pública, em relação a outras duas reaçōes (ELISA e HAP), anteriormente utilizadas no diagnóstico da neurocisticercose.

\section{Material e Método}

As amostras de LCR foram coletadas e conservadas a $-20^{\circ} \mathrm{C}$ até o momento de uso e foram agrupadas em:

a) grupo $D$, constituído de amostras de LCR de 58 pacientes com neurocisticercose, diagnosticados através de dados clínicos, epidemiológicos e laboratoriais (hipertensão intracraniana ou epilepsia ou ambas, neuroimagem compatível com neurocisticercose e LCR com características inflamatórias e anticorpos específicos);

b) grupo S, constituído de 37 amostras de LCR de indivíduos supostamente sadios, com exame quimiocitológico normal. A coleta foi realiza- da por ocasião de raquianestesias ou para controle de alta hospitalar após infecções agudas do sistema nervoso;

c) grupo E, constituído de amostras de 48 pacientes com encefalopatias, de diferentes etiologias (meningites bacterianas e por leveduras).

$\mathrm{O}$ antígeno utilizado foi o extrato salino bruto (ESB) de cisticercos, obtido segundo a metodologia descrita por Costas, empregado com modificações por Vaz e Ferreira ${ }^{17}$.

Foram utilizadas, para a determinação de anticorpos da neurocisticercose, os testes de: EIAC (segundo a técnica de Pialarissi e Nitrini ${ }^{13}$; HAP, segundo a técnica de Ueda e col. ${ }^{15}$, e ELISA, segundo a técnica descrita por Pialarissi e col. ${ }^{12}$ ).

Para fins de análise estatística foram calculados: sensibilidade, especificidade e eficiência dos testes ELISA, HAP e EIAC, além dos índices de concordância (Kappa), entre os testes e a média geométrica (MGT) dos títulos.

\section{Resultados}

São apresentados os resultados das reações de EIAC, ELISA e HAP de pacientes com neurocisticercose e indivíduos sem neurocisticercose, em relação a distribuição de títulos, sensibilidade, especificidade, eficiência e rendimento do antígeno.

A distribuição dos títulos das amostras dos grupos $D, S$ e $E$ é apresentada na Figura 1 .

Os valores dos limiares de reatividade "cut off" adotados (obtidos por cálculo) foram de 1:4 no EIAC, $1: 1$ no ELISA e 1:8 no HAP.

As médias geométricas dos títulos nos três grupos $D, S$ e $E$, com intervalo de confiança de $99 \%$, sâo relacionadas na Tabela 1 .

Pode-se verificar a partir dos dados apresentados na Tabela 2, que a sensibilidade e especificidades foram respectivamente para o teste EIAC $84,5 \%$ e $95,3 \%$, para HAP $77,2 \%$ e $91,8 \%$ e para ELISA $98,2 \%$ e $94,1 \%$.

A eficiência calculada dos testes foi de $98,6 \%$ para ELISA, $90,9 \%$ para EIAC e $84,9 \%$ paa HAP.

Quando se comparou o rendimento de antígeno ESB nos três testes, observou-se que com um volume de $1 \mathrm{ml}$ do mesmo era possível a utilização de 400 cavidades das placas para o teste EIAC, enquanto que para cada um dos outros dois testes esta quantidade de antígeno seria consumida em apenas 40 cavidades, como consequiência da determinação da atividade antigênica e dos protocolos utilizados (Tabela 3 ). 

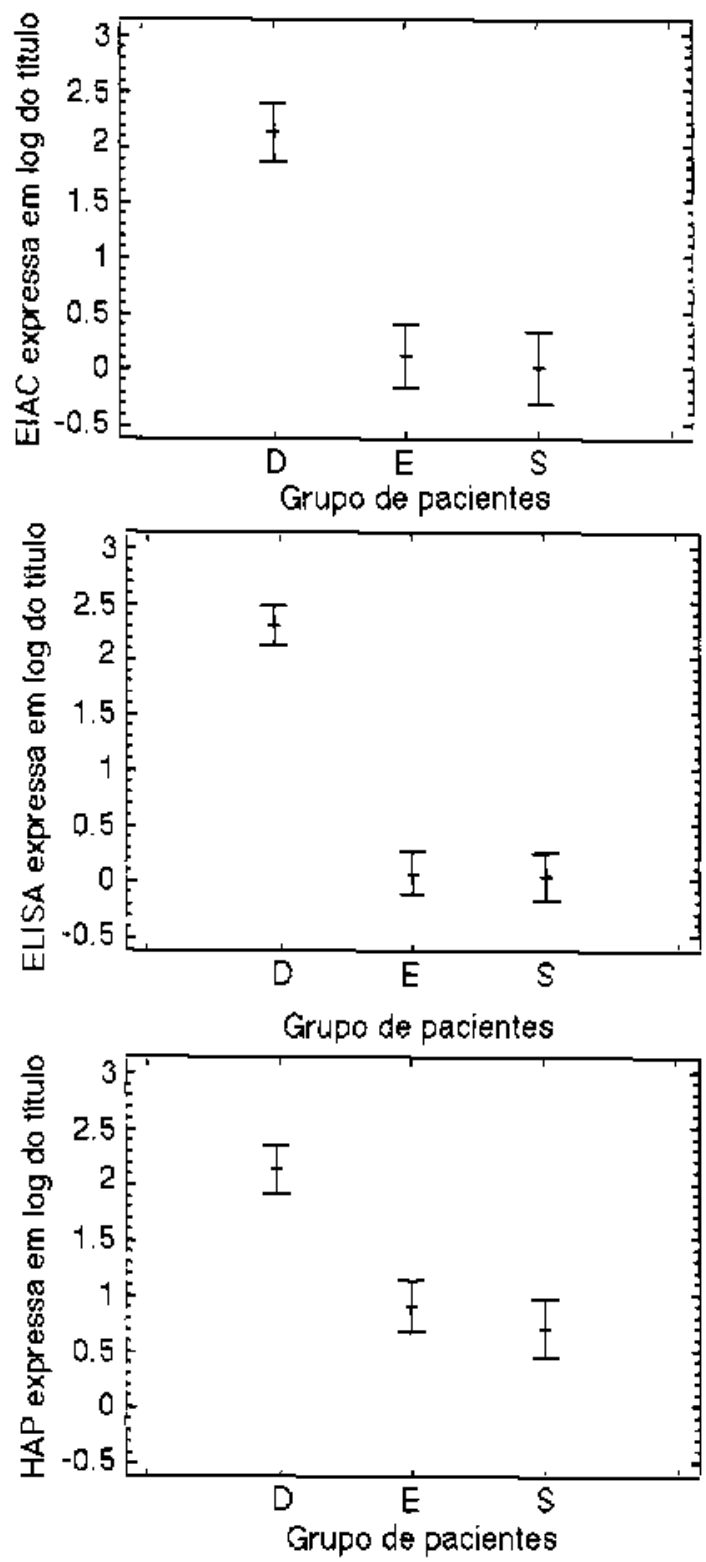

Figura 1 - Distribuição de amostras de LCR dos grupos D, $S$ e nos testes de EIAC, ELISA e HAP. com intervalos de confiança de $99 \%$.
Tabela 1 - Valores das médias geométricas (MGT) dos títulos dos grupos D, S e E, nos testes ELISA, HAP e EIAC.

\begin{tabular}{lcccc}
\hline & & \multicolumn{2}{c}{ Grupos } & \\
\cline { 2 - 3 } Testes & $D$ & $S$ & E \\
\hline ELISA & 208,5 & 1,0 & 1,2 \\
HAP & 30,1 & $t, 0$ & 1,1 \\
EIAC & 134,2 & 1,0 & 1,3 \\
\hline * Ver especificação dos grupos (D, $S$ e E) em \\
"Material e Método"
\end{tabular}

Tabela 3 - Rendimento do antígeno (ESB) nos testes EIAC, ELISA e HAP.

\begin{tabular}{|c|c|c|c|}
\hline Antigeno & EIAC & ELISA & HAP \\
\hline ESB & & & \\
\hline $\begin{array}{l}\text { Atividade antigênica } \\
\text { ( } \mu \text { g proteína/cavidade) } \\
\text { Rendimento na reação } \\
\text { (Cavidade/m!) }\end{array}$ & $\begin{array}{l}0,1 \\
400\end{array}$ & $\begin{array}{c}1 \\
40\end{array}$ & $\begin{array}{c}1 \\
40\end{array}$ \\
\hline
\end{tabular}

\section{Discussão}

As amostras de LCR foram ensaiadas pelo teste de hemaglutinação passiva, que tem sido rotineiramente utilizado em laboratório e referendado pelo Center for Diseases Control (Atlanta, Georgia, EUA) ${ }^{18}$, também pelo teste imunoenzimático (ELISA) recomendado pela Organização Panamericana de Saúde ${ }^{2}$, e pelo teste de eritroimunoadsorção por captura padronizado para a neurocisticercose, no Instituto Adolfo Lutz (São Paulo) ${ }^{13}$. Este último teste já foi utilizado para outras doenças e classes de imunoglobulinas ${ }^{10}$, e utiliza o princípio das reações de aglutinação semelhante à reação de

Tabela 2 - Resultados dos testes EIAC, ELISA e HAP em pacientes com neurocisticercose e em individuos sem neurocisticercose. Sāo Paulo, 1994.

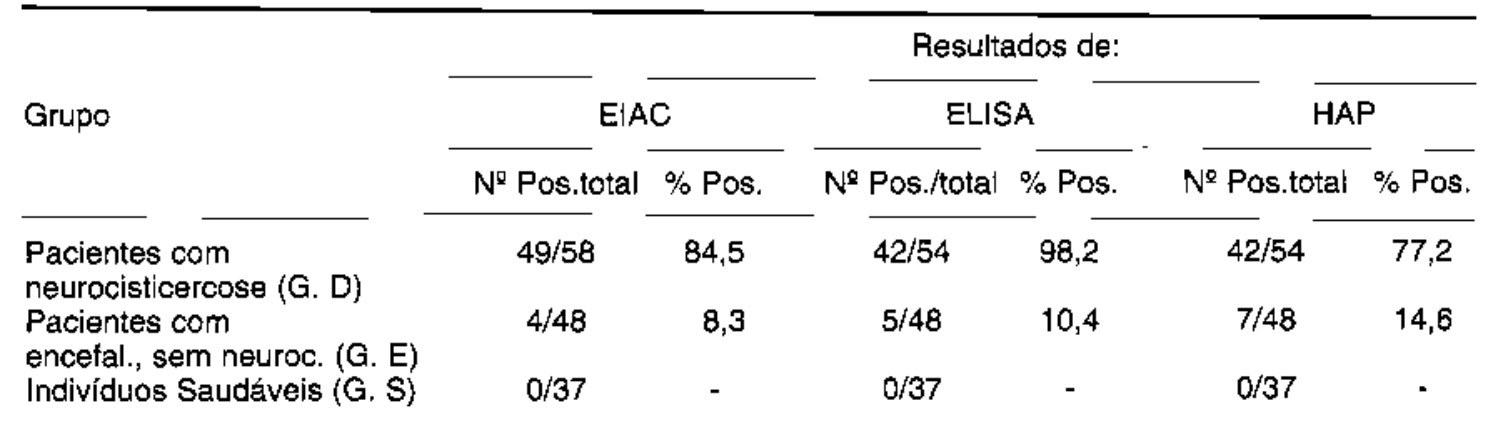


hemaglutinação passiva. Na reação de HAP, tanto anticorpos da classe IgG quanto da classe IgM estarão se ligando às hemácias sensibilizadas. Nos testes ELISA e EIAC, por serem testes de captura, somente uma classe de imunoglobulina (IgG ou IgM) será detectada, pois esta classe é previamente capturada por um imunosoro classeespecífico. Portanto, uma diferença entre EIAC. ELISA e HAP reside no fato de que nos dois primeiros testes os anticorpos detectados podem ser de uma determinada classe (por exemplo IgG). Nos testes de EIAC e ELISA torna-se possível evitar a competição dos anticorpos IgM, que podem não ser específicos do antígeno utilizado, e quando presentes podem se ligar com uma eficiência de até 750 vezes mais. ${ }^{1 \mathrm{I}}$

Isto implica uma menor sensibilidade do teste HAP em relação aos testes de captura, o que pode ser observado pelo resultado da sensibilidade dos testes (Tabela 2). Da mesma forma, observa-se uma menor especificidade da HAP em relação a ELISA a EIAC, com vantagem destes dois testes, onde anticorpos (IgG), classe específica, sāo detectados.

Ainda comparando-se os três testes, pode-se observar que, embora a concentração protéica de ESB tenha sido de $40 \mu \mathrm{g} / \mathrm{ml}$, no teste EIAC, maior que a utilizada para o teste de ELISA $(10 \mu \mathrm{g} / \mathrm{ml})$, o rendimento do ESB no EIAC, por um volume unitário de antígeno, foi 10 vezes maior do que nos testes de ELISA e HAP. Isto, porque, com $1 \mathrm{ml}$ do antígeno foi possivel empregá-lo em 400 cavi- dades de placas, enquanto que nos outros dois testes só foi possível empregá-lo em 40 cavidades, de acordo com as metodologias empregadas, previamente descritas ${ }^{12,13,15}$.

Para diagnóstico individual recomendam-se testes de maior sensibilidade, isto é, testes com capacidade de detectar o maior número de casos verdadeiramente positivos da doença, o que é muito importante na neurocisticercose, onde o diagnóstico é sempre difícil. Já para inquéritos epidemiológicos, também são importantes os testes diagnósticos com boa especificidade, isto é, testes que possam detectar com grande certeza que os indivíduos negativos na população são verdadeiramente negativos. O EIAC apresenta uma vantagem em relação ao ELISA por ser de menor custo, fator importante para os laboratónios de saúde pública, onde a maioria dos casos de neurocisticercose são diagnosticados.

Concluiu-se que os testes apresentaram desempenho decrescente na seguinte ordem: ELISA, EIAC, HAP conforme observado pelos valores de eficiência de cada um.

A maior concordancia dos resultados ocorreu entre ELISA e EIAC (Kappa $=0,78)$. O melhor desempenho do teste ELISA em relação a HAP confirma dados previamente apresentados por Pialarissi e col. ${ }^{12}$ e sugere que seja o teste de escolha, sempre que possível. A mais alta especificidade calculada para o teste EIAC indica que é um teste adequado para confirmar um diagnóstico.

\section{Referências Bibllográflcas}

1. ARAMBLLO III. P.V.; WALIS, K.W.; BLLLOCK, S.: KAGAI: I.G. Serodiagnosis of human cysticercosis by microplate enzyme-linked immunospecific assay (ELISA). Acta Trop.. 35:63-7, 1978 .

2. ALARCON DE NOYA, B.: BERRO. O.J.; COLTORTI, E.A.: FLISSER, A.: STRALISS, W.; VAZ, A.J. Informe de la reunión técnica sobre nomatización y estrategias para la implementación del immunodiagnóstico de la cisticercosis humana, Buenos Aires, 1989, Ret. Inst. Med. Trop. S. Paulo, 31:291-3, 1989.

3. RIAGI, F.: NAVARRETI, F,: PINA, A.; SANTIAGO, A.M.: TA-PLA. L. Estudio de tres reacciones serologicas en el diagnóstico de la cisticercosis. 25:501-8, 1961.

Ret. Wed. Hosp. Gral. Mexico.

4. COSTA, J.M.; FERREIRA. A.W.: MAKIYO, M.M: CAMARGO. M.E. Spinal fluid immunoenzimatic assay (ELISA) for neurocysticercosis.

Ret: Inst. Med. Trop. S. Paulo, 24:337-41. 1982.

5. COSTA, J.M. Teste imunoenzimático (ELISA) no diagnóstico da neurocisticercose. Sào Paulo, 1983. [Tese de Doutorado - Instituto de Ciências Biomédicas da [SP].

6. ESPINOZA, B.; FLISSER, A, PANCARTE, A; LARRALDE, C. Immunodiagnosis of human cysticercosis: ELISA and immunoelectrophoresis. In: Flisser. A.: Willms, K.; Laclette, J.P.; Larralde. C.; Ridaura. C.: Beltrán, F. ed. Cysticercosis: present state of knouledge and perspectives. New York. Academic Press. 1982 p. 163-70.

7. FLISSER, A:: TARRAB, R.; WILLMS, K.: LARRALDE, C. Immunoelectrophoresis y doble immunodifusion en el diagnóstico de la cisticercosis cerebral humana. Arcb.Invest.Méd. 6:1-12, 1975.

8. KRECH, L. \& WILHELM. J.A. A solid-phase imnunosorbent technique for the rapid detection of rubella IgM by haemmagglutination inhibition. J.Gen.Virol., 44: 281-6, 1979. 
9. LANGE, O. Síndromo liquórico da cisticercose encéfalo-meningéia. Rev. Neurol. Psiquiat. S. Paulo, 6: $35-48,1940$.

10. LOGT, T.M. van der; LOON, A.M. van; VEEN, J. van der. Hemadsorption immunosorbent technique for determination of rubella immunoglobulin $M$ antibody, J. Clin. Microbiol., 13:410-5, 1981.

11. NAKAMURA, R.M.; TUCKIER, E.S.; CARLSON, I.H. Immunoassays in the clinical laboratory. In: Henry, J.B., ed. Clinical \& diagnosis management by laboratory methods, 18th ed. Philadelphia, W.B. Saunders, 1991. p. 860-2.

12. PLALARISSI, C.S.M.; VAZ, A.J.; SOUZA, A.M.C.; NAKAMURA, P.M.; CAMARGO, E.D.; SILVA, M.V.; UEDA, M. Estudo comparativo de testes sorológicos no diagnóstico imunologico da neurocisticercose. Rev. Inst. Med. Trop. S. Paulo, 29: 367-73, 1987.

13. PIALARISSI, C.S.M. \& NITRINI, S.M.O.O. Utilização do teste de eritroimunoadsorção por captura no imunodiagnóstico da neurocisticercose. Rev. Saude Püblica, 28: 116$20,1994$.

14. SPINA-FRANÇA, A.; LIVRAMENTO, J.A.; BACHESCHI, L.A.; GARCIA-LOPES, P. Cerebrospinal fluid immunoglobulins in cysticercosis of the central nervous system. Arq. Neuro-Psiquiat., 34: 40-5, 1976.
15. UEDA, M.; CAMARGO, E.D.; VAZ, A.J.; SOUZA A.M.C.; FIGUEIREDO, R.M.; SILVA, M.V. Passive haemagglutination test for human neurocysticercosis. I. Standardization and evaluation of the passive haemagglutination test for the detection of anti-Cysticercus cellulosae antibodies. Rev. Inst. Med. Trop. S. Paulo, 30: 51-6, 1988.

16. UEDA, M.; VAZ, A.J.; CAMARGO, E.D.; SOUZA, A.M.C.; BEVELLI, R.M.F.; SILVA, M.V. Passive haemagglutination test for human neurocysticercosis immunodiagnosis. II. Comparison of two standardized procedures for the passive haemagglutination reagent in the detection of anti-Cysticencus cellulasae antibodies in cerebrospinal fluids. Rev. Inst. Med. Trop. S. Paulo, 30: $57-62,1988$

17. VAZ, A.J. \& FERREIRA, A.W. Imunodiagnóstico da neurocisticercose: teste imunoenzimático com antígenos quimicamente ligados a suportes para a pesquisa de anticorpos em soro e líquido cefalorraquiano. Rev. Inst. Med. Trop. S. Paulo, 30: 1-10, 1988.

18. WALIS, K.W. Serodiagnostic test for parasitic diseases. In: Lennette, E.H.; Balows, A.; Hausler Jr., W.J.; Shadomy, H.J., ed. Manual of clinical microbiology. 4th ed. Washington, American Socjety for Microbiology, 1985. p. 945-8.

\begin{abstract}
Comperisons were made among the erythroimmunoadsorption by capture (C-EIA), the immunoenzymatic (EL/SA) and passive haemaglutination (P.H.A.) tests used in the diagnosis of neurocysticercosis. The three tests, two of them routine by in diagnosis, and the third one (C-EIA) recently, standardised were compared for the detection of antiCystlcercus cellulosae antibodies. In the three reactions the antigen utlized was raw saline extract (R.S.E) with a yield of $0.1,1$ and $10 \mu g$ protein/cavity for the C-EIA, ELISA and P.H.A tests, respectively. In a group of 58 patients with neurocysticercosis, the sensitivity to the ELISA, C-EIA and P.H.A tests was of $98.2 \%, 84.5 \%$ and $77,2 \%$, respectively. in the control group of 85 individuals, healthy or with encephalopathies other than neurocysticercosis, the sensitivity was of $98.27 \%, 84.48 \%$ and $79.63 \%$, respectively, and the specificity was of $94.1 \%, 95.3 \%$ and $91.8 \%$. This order of choice should be followed, depending on the resources available.
\end{abstract}

Oysticercosis, diagnosis. Immunasorbent techniques, utlization. Enzyme-linked immunosorbent assay, utilization. Hemmagglutination tests, utlization. 